\title{
Prevalence of Hypertension Among Obese Children and Effect of Environmental Factors on Hypertension and Childhood Obesity: A School Based Study
}

\author{
Anjan kumar V S ${ }^{1}$, Bhagyalakshmi V S *2, Rajesh T ${ }^{3}$, Arumugam A 4. \\ *2 Department of Physiology, S V M edical College, Tirupati, Andhra Pradesh, India. \\ 1,3,4 Department of Paediatrics, S V Medical College, Tirupati, Andhra Pradesh, India.
}

\section{ABSTRACT}

Introduction: Childhood obesity as an important risk factor for cardiovascular and metabolic diseases in the later part of life are more susceptible to develop hypertension and coronary artery diseases. The effect of altered environmental factors may lead to hypertension and childhood obesity.

Aim and objectives: To evaluate the incidence of hypertension among obese children and the effect of environmental factors on hypertension and obesity.

Results: Out of 1000 school going children, 85 were having $\mathrm{BMI}>85^{\text {th }}$ centile. Among 85,53 were overweight and 32 being obese. SBP and DBP were significantly higher in obese children when compared to non obese group $(p<0.05)$. A positive correlation between age, weight, height, BMI with SBP $(p<0.05)$ while a negative correlation between weight, BMI and hours of sleep per day $(p<0.05)$.

Conclusion: A higher prevalence of systolic and diastolic hypertension was observed among children with obesity. It is implicated that decreased hours of sleep, milk consumption, physical activity and increased sedentary life style are important risk factors in childhood obesity.

KEY WORDS: Environmental factors-Hypertension-Childhood obesity.

Address for correspondence: Dr. Bhagyalakshmi V S, Department of Physiology, S V M edical College, Tirupati, Andhra Pradesh, India. E-Mail: drvsblmbs@gmail.com

\begin{tabular}{|l|ll|}
\multicolumn{3}{|c|}{ Online Access and Article Informtaion } \\
\hline Quick Response code & \multicolumn{2}{|c|}{ International Journal of Integrative Medical Sciences } \\
\cline { 2 - 3 } & \multicolumn{2}{|c|}{ www.imedsciences.com } \\
\cline { 2 - 3 } & Received: 16-03-2015 & Accepted: 25-03-2015 \\
Dol: $10.16965 /$ ijims.2015.108 & Reviewed: 16-03-2015 & Published: 31-03-2015 \\
\hline Source of Funding: Self & \multicolumn{2}{|c|}{ Conflicts of interest: None } \\
\hline
\end{tabular}

\section{INTRODUCTION}

Obesity is a disorder of energy balance affecting wide range of people belonging to diverse ethnic groups, age and socioeconomic status. Obesity has become an increasingly important medical problem in children and adolescents. Many of the outcomes associated with obesity that was previously thought of as diseases of adults are now affecting children. Outcomes related tochildhood obesity include hypertension, type 2 diabetes mellitus, dyslipidemia, left ventricular hypertrophy, nonalcoholic steatohepatitis, obstructive sleep apnea, and orthopedic problems (such as slipped capital-femo ral epiphysis), as well as social and psychological problems [1]. Prevalence of overweight and obesity is increasing in children and adolescents in India as reflected in various studies conducted in various states and regions of India [2-4].

Hypertension is one of the most important, potent and non modifiable universal contributor to majority of non communicable diseases including cardiovascular and cerebrovascular diseases leading to significant morbidity and mortality worldwide and India. Studies on hypertension in childhood have the important 
impact on child health with possible control and prevention of high blood pressure before its harmful sequelae can occur. The prevalence of hypertension in children is reported to range from a high of $16.2 \%$ to a low of less than $1.0 \%$ $[5,6]$. This diverse prevalence of hypertension may vary in different ages with different criteria adopted to define hypertension and differences between racial sub-groups such as geographic, environmental and cultural factors. The causes of childhood obesity and hypertension are manifold that include modifiable factors such as lack of regular exercise, sedentary habits, over consumption of high calorie foods, sleep duration and other various environmental factors. The present study was conducted in apparently healthy school children to look at the incidence of obesity hypertension among obese children and to evaluate the effect of environmental factors on obesity and hypertension.

\section{MATERIAL AND METHODS}

Patients: The present cross sectional study was conducted among one thousand apparently normal school children in the age group of 10 15 years. The age of each participant was recorded in completed years and verified from school records belonging to four different schools located in Tirupati, Andhra Pradesh. Schools included in the present study were selected by simple random sampling method. All the necessary details regarding the study were informed to school management, teachers and children. A detailed informed consent was taken from each participant.

Anthropometric measurements such as weight $(\mathrm{Kg})$ and height $(\mathrm{m})$ were measured by standardized techniques. The calculated Body Mass Index (BM I) using weight and height was plotted on CDC $2000 \mathrm{BM}$ I centile charts and the children were categorized into normal $\left(\varangle 85^{\text {th }}\right.$ centile), over weight $\left(85^{\text {th }}-95^{\text {th }}\right.$ centile) and obese ( $>95^{\text {th }}$ centile) [7].

Measurement of Blood pressure (BP) was recorded as per the recommendations of $4^{\text {th }}$ US task force report on hypertension [8]. All subjects were advised 5 minutes rest in sitting posture followed by measurement of systolic and diastolic blood pressure on right arm using standard mercury sphygmomanometer. The average of three consecutive readings was taken as the blood pressure of the child. Children were categorized into normal $\left(<90^{\text {th }}\right.$ centile) prehypertension $\left(90^{\text {th }}-95^{\text {th }}\right.$ centile) and hypertension ( $>95^{\text {th }}$ centile).

The main purpose of the present study i.e., effect of various environmental factors on obesity and hypertension were assessed by using standard questionnaire containing proforma that includes schooling hours per day, hours of physical activity per week, hours of sleep per day, frequency of skipping breakfast per month, hours of television viewing and amount of milk intake per day.

Statistical analysis: Data was expressed as mean \pm standard deviation (SD) and frequencies for continuous and categorical variables respectively. Comparison of continuous and categorical variables was analyzed by independent sample t-test and Chi-square analysis respectively. Association among various parameters was analyzed using Pearson correlation analysis. A $P \leq 0.05$ was considered significant for this study.

\section{RESULTS}

In the present study, the mean age observed as $12.1 \pm 1.7$ years. Out of 1000 subjects, $85(8.5 \%)$ were above $\mathrm{BM} \mathrm{I}>85^{\text {th }}$ centile and form the study group. Ámong 85 children, 59 (69.4\%) were boys and $26(30.6 \%)$ were girls. Sub categorization of children with $\mathrm{BMI}>85^{\text {th }}$ centile revealed that 53 (62.4\%) and 32 (37.6\%) were overweight and obese respectively. The mean weight, height, BMI, systolic blood pressure and diastolic blood pressure among boys and girls is shown in table1.

Prevalence of various stages of hypertension among study group was represented in table- 2 . M easurement of systolic blood pressure among children with $\mathrm{BM} I>85^{\text {th }}$ centile has shown that $13.6 \%$ and $22 \%$ were having prehypertension and systolic hypertension, while diastolic blood pressure measurement has showed that $18.7 \%$ and $33.8 \%$ were with prehypertension and diastolic hypertension respectively. Categories of systolic and diastolic hypertension among boys and girls are shown in figure $1 a$ and $1 b$ respectively. 
Anjan kumar V S et al. Prevalence of Hypertension Among Obese Children and Effect of Environmental Factors on Hypertension and Childhood Obesity: A School Based Study.

Table 1: M ean weight, height, BMI, SBP and DBP among boys and girls among study group.

\begin{tabular}{|c|c|c|c|}
\hline Parameter & Boys $(\mathbf{n = 5 9 )}$ & Girls $(\mathbf{n = 2 6 )}$ & P-value \\
\hline Mean weight & $57.5 \pm 12.0$ & $51 \pm 11.9$ & $>0.05$ \\
\hline Mean height & $151.6 \pm 20.9$ & $147.7 \pm 13.1$ & $>0.05$ \\
\hline Mean BMI & $24.1 \pm 2.7$ & $23.4 \pm 2.7$ & $>0.05$ \\
\hline $\begin{array}{c}\text { Systolic blood } \\
\text { pressure }\end{array}$ & $112.8 \pm 13.3$ & $115.6 \pm 15.3$ & $>0.05$ \\
\hline $\begin{array}{c}\text { Diastolic blood } \\
\text { pressure }\end{array}$ & $75.6 \pm 9.7$ & $78 \pm 9.6$ & $>0.05$ \\
\hline
\end{tabular}

Fig. 1a: Prevalence of systolic hypertension among obese boys and girls.

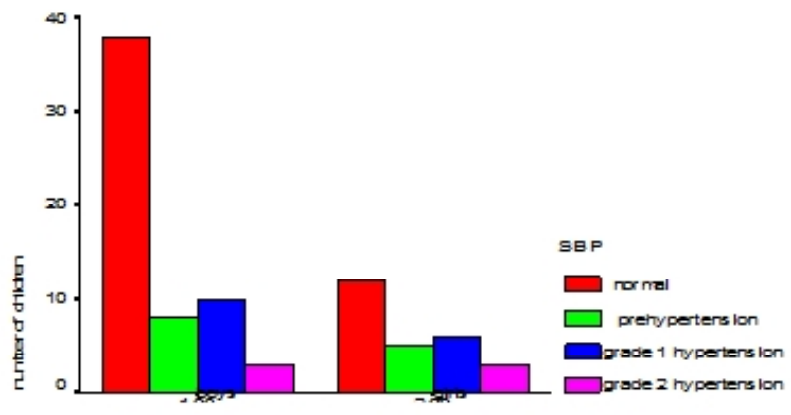

Fig. 1b: Prevalence of diastolic hypertension among obese boys and girls.

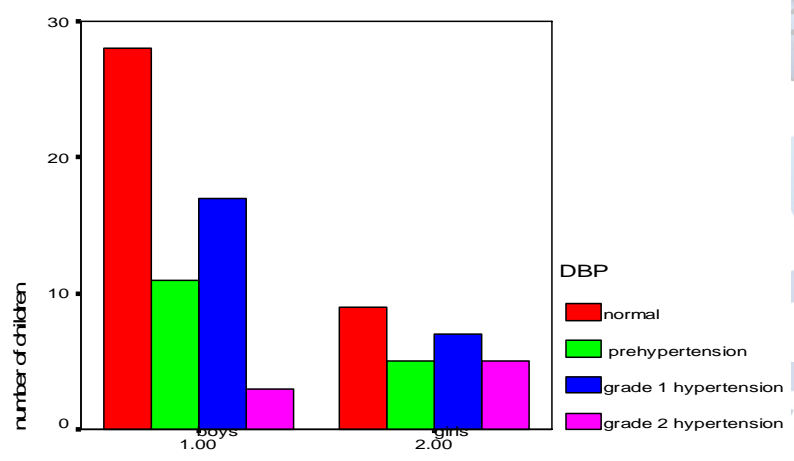

Table 3: Various environmental factors studied among obese children.

\begin{tabular}{|c|c|c|}
\hline Parameter & Mean \pm SD & Range \\
\hline $\begin{array}{c}\text { Sedentary life style } \\
\text { (hrs/ day) }\end{array}$ & $11.5 \pm 1.5$ & $8.0-15.0$ \\
\hline $\begin{array}{c}\text { Physical activity } \\
\text { (hrs/ week) }\end{array}$ & $1.3 \pm 0.7$ & $0.5-3.0$ \\
\hline Schooling (hrs/ day) & $9 \pm 1.3$ & $6.0-11.0$ \\
\hline T.V view ing (hrs/ day) & $1.3 \pm 1$ & $0.0-8.0$ \\
\hline Sleep (hrs/ day) & $8.1 \pm 0.9$ & $6.0-10.0$ \\
\hline $\begin{array}{c}\text { Amount of milk intake } \\
\text { (glass of 200m / day) }\end{array}$ & $0.9 \pm 0.8$ & $0.0-5.0$ \\
\hline
\end{tabular}

significantly higher in obese children when compared to non obese children $(P<0.05)$. In contrast, average milk intake and hours of physical activity per week have showed to be significantly lower in children with obesity when compared with non obese children ( $P \varangle 0.05)$. In addition, children with childhood obesity showed significantly higher SBP and DBP when compared to non obese children $(P<0.05)$. Hence, it is inferred that children with higher BMI, leading more sedentary lifestyle with lower consumption of milk and decreased physical activity are more predisposed to childhood obesity and are observed with hypertension.

Association of demographic parameters, blood pressure and environmental factors among obese children has showed the following results. A significant positive correlation was observed between age, weight, height, BM I and systolic blood pressure alone $(p \varangle 0.05)$ concluding that

\begin{tabular}{|c|c|c|c|c|}
\hline Parameter & Normal & $\begin{array}{c}\text { Pre } \\
\text { hypertension }\end{array}$ & Stage 1 HTN & $\begin{array}{c}\text { Stage 2 } \\
\text { HTN }\end{array}$ \\
\hline \multicolumn{5}{|c|}{ Systolic blood pressure } \\
\hline Boys & $38(64.4 \%)$ & $8(13.6 \%)$ & $10(17 \%)$ & $3(5 \%)$ \\
\hline Girls & $12(46.1 \%)$ & $5(19.3 \%)$ & $6(23.1 \%)$ & $3(11.5 \%)$ \\
\hline \multicolumn{5}{|c|}{ Diastolic blood pressure } \\
\hline Boys & $28(47.5 \%)$ & $11(18.7 \%)$ & $17(28.8 \%)$ & $3(5 \%)$ \\
\hline Girls & $9(34.7 \%)$ & $5(19.2 \%)$ & $7(26.9 \%)$ & $5(19.2 \%)$ \\
\hline
\end{tabular}

Table 2: Prevalence of variousstages of hypertension among study group.
The important objective of the present study was evaluation of effect of environmental factors on childhood obesity and hypertension. The mean values of the environmental factors among study group included were shown in table-3. The effect of environmental factors among study group was compared with 85 non obese, age $\&$ sex matched children. It was observed that mean weight, BM I and sedentary hours per day were children with increased BM I are more susceptible to elevated systolic blood pressure. However, hours of sleep per day had a significant negative correlation ( $p<0.05$ ) with weight and BM I. Height had a significant positive correlation with the amount of milk intake per day $(p<0.05)$ suggesting the negative impact of hours of sleep per day on increased weight and positive impact of milk consumption with growing height. 
Anjan kumar V S et al. Prevalence of Hypertension Among Obese Children and Effect of Environmental Factors on Hypertension and Childhood Obesity: A School Based Study.

\begin{tabular}{|c|c|c|c|c|}
\hline Parameter & $\begin{array}{c}\text { Obese children } \\
\text { (Mean } \pm S D)\end{array}$ & $\begin{array}{c}\text { Nonobese children } \\
\text { (Mean } \pm \text { SD) }\end{array}$ & P-value & \multirow{12}{*}{$\begin{array}{l}\text { Table 4: Comparison of effect of environ- } \\
\text { mental factors among obese children } \\
\text { and nonobese controls. }\end{array}$} \\
\hline Weight (Kg) & $55.5 \pm 12.3$ & $45 \pm 10$ & $\varangle 0.001 *$ & \\
\hline Height & $150 \pm 18.9$ & $154 \pm 10.9$ & 0.08 & \\
\hline BMI & $23.9 \pm 2.7$ & $18.6 \pm 2.4$ & $\varangle 0.001 *$ & \\
\hline $\begin{array}{c}\text { Milk intake (glass } \\
\text { of } 200 \mathrm{ml} / \text { day) } \\
\end{array}$ & $0.9 \pm 0.8$ & $1.5 \pm 0.9$ & $\triangleleft .001^{*}$ & \\
\hline $\begin{array}{l}\text { Sedentary } \\
\text { hours/ day }\end{array}$ & $12.8 \pm 11.9$ & $10 \pm 2.4$ & $0.048 *$ & \\
\hline $\begin{array}{c}\text { Hours of TV } \\
\text { viewing }\end{array}$ & $1.3 \pm 1.1$ & $1.2 \pm 0.6$ & 0.51 & \\
\hline Sleep hours/ day & $8.1 \pm 0.9$ & $7.9 \pm 0.8$ & 0.16 & \\
\hline \begin{tabular}{|c}
$\begin{array}{c}\text { Physical activity } \\
\text { (hours/ wk) }\end{array}$ \\
\end{tabular} & $1.7 \pm 2.3$ & $2.3 \pm 0.7$ & $\varangle 0.001^{*}$ & \\
\hline SBP (m m Hg) & $113 \pm 13$ & $107 \pm 8$ & $\varangle 0.001 *$ & \\
\hline $\mathrm{DBP}(\mathrm{mm} \mathrm{Hg})$ & $76 \pm 9$ & $72 \pm 6$ & $0.003 *$ & \\
\hline $\begin{array}{c}\text { Skipping } \\
\text { breakfast/ month }\end{array}$ & $1.3 \pm 4$ & $0.56 \pm 1.5$ & 0.1 & \\
\hline
\end{tabular}

\section{DISCUSSION}

Childhood obesity is an important non communicable disease that is epidemic globally. It is estimated that $\mathbf{1 7 . 6}$ million children under five years of age are overweight worldwide. In the United States, the prevalence and severity of overweight status is clearly increasing among children. In national surveys from the 1960 s to the 1990s, the prevalence of overweight in children grew from $5 \%$ to $11 \%$ [9]. This increase in the severity of obesity has also translated into an increase in the prevalence of outcomes such as type 2 diabetes mellitus, hypertension and cardiovascular diseases [2]. In our study, we found a prevalence of $8.5 \%$ with childhood obesity in comparison to international figures [9].

The association between obesity and hypertension in children has been reported in numerous studies among a variety of ethnic and racial groups. All studies signifying elevated blood pressures with higher prevalence of hypertension in obese compared with lean children $[2,10]$. In our study, there was a high prevalence of systolic hypertension (22\%) and diastolic hypertension (33.8\%) among obese children. There was a significant positive correlation of systolic blood pressure in obese children with age, weight, height, BM I as shown in previous studies [11-14].

There was a significant negative correlation of number of hours of sleep with BM I. Short sleep duration has been shown to be a risk factor for obesity in children. It is proposed that modulation of hormones such as decreased leptin and ghrelin can increase hunger, appetite, and influence weight gain [15-16]. The duration of sleep in this study was self reportage. Obese children are less physically active, had more sedentary hours per day and consume less milk per day. The blood pressure records were significantly less among controls compared to obese children. Dairy calcium promotes weight loss was substantiated in this study in comparison to non obese children.

\section{CONCLUSION}

Based on the results of the present study, it concludes a higher prevalence of obesity among apparently healthy school children that is been unnoticed. Prevalence of systolic and diastolic hypertension was higher among obese children. It is implicated that decreased hours of sleep, milk consumption, physical activity and increased sedentary life style are important risk factors in childhood obesity.

\section{REFERENCES}

[1]. Dietz WH. Health consequences of obesity in youth: childhood predictors of adult disease. Pediatrics 1998 Mar;101(3):518-25.

[2]. Verma M, Chhatwal J, George SM. Obesity and hypertension in children. Indian Paediatr 1994; 31: 1065-9.

[3]. Chhatwal J, VermaM, Rial SK. Obesity among preadolescent and adolescents of a developing country(India). Asia Pac J. Clin Nutr 2004;13:2315. 
[4]. Marwaha RK, Tandon N, singh Y, aggarwal R, Grewal K, Mani K. A study of growth parameters and prevalence of overweight and obesity in school children from Delhi. Indian pediatr 2006;43:94352.

[5]. Sachdev Y. Normal blood pressure and hypertension in Indian children. Indian pediatr 1984;21:41-48.

[6]. Chadha SL. Tandon R, Shekhawat S, Gopinath N. An epidemiological study of blood pressure in school children (5-14 Yrs) in Delhi. Indian heart J 1999;51:178-182.

[7]. Department of health and human services. Centers for disease control and prevention,USA. CDC growth charts for the united states [database on the internet]. Available at http://www.cdc.gov/nchs/ data/nhanes/growthcharts/score/bmiagerev.x/s

[8]. National High Blood Pressure Education Program Working Group on High Blood Pressure in Children and Adolescents. The fourth report on the diagnosis, evaluation, and treatment of high blood pressure in children and adolescents. Pediatrics 2004;114:555-76.

[9]. WHO. Obesity and overweight. Fact sheet. http:// www.who.int/ mediacentre/ factsheets/fs311/en/ updated on January 2015.

[10]. Andriska], Gombik M, Breyer H, Tarr A. Hypertension in children and adolescents: Results of a long term follow up study. Clin Exper Theory Practice 1986; A8:567-79.
[11].Mohan B, Kumar N, Aslam N, Rangbulla A, Kumbkarni S, Sood NK, Wander GS: Prevalence of sustained hypertension and obesity in urban and rural school going children in Ludhiana. Indian Heart J 2004; 56:310-14.

[12]. Lu X, Shi P, Luo CY, Zhou YF, Yu HT, Guo CY et al. Prevalence of hypertension in overweight and obese children from a large school-based population in Shanghai, China. BM C Public Health. 2013 Jan 11;13:24.

[13]. Raj M, Sundaram KR, Paul M, Deepa AS, Kumar RK. Obesity in Indian children: time trends and relationship with hypertension. Natl Med J India. 2007 Nov-Dec;20(6):288-93.

[14]. Baradol RV, Patil SV, Ranagol A. Prevalence of overweight, obesity and hypertension amongst school children and adolescents in North Karnataka: A cross sectional study. Int J M ed Public Health 2014;4(3):260-4.

[15]. Taheri S, Lin L, Austin D, Young T, M ignot E. Short Sleep Duration Is Associated with Reduced Leptin, Elevated Ghrelin, and Increased Body M ass Index. PLoSM ed. 2004 Dec; 1(3): e62.

[16]. Speigel K,Tasali E, Leproult R, Cauter EV. Effects of poor and short sleep on glucose metabolism and obesity risk. Nature Reviews Endocrinology 2009 May; 5: 253-61.

How to cite this article: Anjan kumar V S, Bhagyalakshmi V S, Rajesh T, Arumugam A. Prevalence of Hypertension Among Obese Children and Effect of Environmental Factors on Hypertension and Childhood Obesity: A School Based Study. Int J Intg Med Sci 2015;2(3):99-103. DOI:10.16965/ijims.2015.108 